\title{
Electrocardiographic Changes in Diabetes Mellitus
}

\section{O. KITTNAR ${ }^{1}$}

${ }^{1}$ Institute of Physiology, First Faculty of Medicine, Charles University, Prague, Czech Republic

Received May 27, 2015

Accepted June 19, 2015

On-line December 15, 2015

\section{Summary}

Diabetes mellitus (DM) has been known for many years to be associated with poor cardiovascular prognosis. Due to the sensitive neuropathy, the coronary artery disease in diabetic patients is frequently asymptomatic. Also twelve leads resting ECG can be within normal limits even in an advanced stage of coronary artery disease. Therefore in addition to the standard ECG other electrocardiographic procedures started to be studied in order to find some typical signs of myocardial damages caused by DM. Repeatedly reported results showed in DM patients without cardiovascular complications the tachycardia, shortening of the QRS and QT intervals, increase of the dispersion of QT interval, decreased amplitudes of depolarization waves, shortened activation time of ventricular myocardium and a flattening of $T$ waves confirmed by the lower value of maximum and minimum in repolarization body surface isopotential maps. Most of these changes are even more pronounced in patients with cardiac autonomic neuropathy. Comparison with similar ECG changes in other diseases suggests that the electrocardiographic changes in DM patients are not specific and that they are particularly caused by an increased tone of the sympathetic nervous system what was indirectly confirmed by the heart rate variability findings in these patients.

\section{Key words}

Electrocardiography • ECG Body Surface Mapping • Heart rate variability $\bullet$ Diabetes mellitus

\section{Corresponding author}

O. Kittnar, Institute of Physiology, $1^{\text {st }}$ Medical Faculty, Charles University, Albertov 5, 12800 Prague 2, Czech Republic. E-mail: okittnar@lf1.cuni.cz

\section{Introduction}

Diabetes mellitus (DM) has been known for many years to be associated with poor cardiovascular prognosis (Kannel et al. 1986). As the development of macrovascular changes can take a relatively long time, twelve leads resting electrocardiogram (ECG) fails very often in diagnosis of coronary artery disease in diabetic patients suffering from DM of type 1 (Alberti and Zimmet 1998, Beckman et al. 2002, Zellweger and Pfisterer 2001). Therefore in addition to the standard ECG other electrocardiographic procedures started to be studied in order to find some typical signs of myocardial damages caused by DM.

Apart from cardiovascular morbidity DM is also associated with microvascular complications including autonomic neuropathy (Alberti et al. 1978). The impaired parasympathetic control of heart rate was observed but no differences in vascular sympathetic control were detected (Javorka et al. 2005). The relatively increased sympathetic control in patients with autonomic neuropathy is associated with the higher risk of sudden cardiac death (Alberti et al. 1978, Alberti and Zimmet 1998). In these patients the heart rate is accelerated and cardiac response to the different stimuli is pathological as far as autonomic neuropathy produces some abnormalities in heart electrical field (Ruttkay-Nedecky 2001, Javorka et al. 2005).

Regardless of the fact if DM is or is not complicated with autonomic neuropathy some general abnormalities in electrocardiograms were repeatedly reported in DM patients. Typically impairments of ECG parameters associated with the DM were found in QT region of electrocardiogram.

The QT interval on the electrocardiography 
reflects the total duration of ventricular depolarization and repolarization, and its measurement has been proposed as a simple and noninvasive method for the cardiovascular mortality in various conditions, including DM (Ewing et al. 1991, Rossing et al. 2001, Maser et al. 2003). Since the QT interval differs inversely with heart rate, heart rate-corrected QT (QTc) interval is preferably used. In patients with DM, QTc prolongation and autonomic dysfunction are closely correlated, and QTc prolongation is considered to be a specific sign of autonomic cardiac dysfunction and high mortality risk (Rossing et al. 2001, Khoharo and Halepoto 2012). The lengthening of QTc in the ECG was observed in patients with diabetes mellitus type 1 (DM 1) both with and without autonomic neuropathy suggesting that autonomic dysfunction does not contribute to hypoglycemia-induced QTc prolongation (Heller 2002).

Physiologically, QTc interval prolongation reflects prolonged total duration of ventricular myocardial repolarization. It has been reported that not only hypocalcaemia and medication, but also heart failure and ischemic heart disease are involved in QTc interval prolongation (Breidthardt et al. 2007, Brooksby et al. 1999). The abnormalities in cardiac repolarization can indicate an increased risk of ventricular tachycardia or even ventricular fibrillation (Marques et al. 1997) and moreover, a prolonged QTc interval was found to increase the rates of all causes of death (de Bruyne et al. 1999).

An increase in the QT interval and its dispersion were also proved to be caused by the insulin hypoglycemia in DM 1 patients (Heller 2002).

Also women with gestational diabetes mellitus (GDM) are at increased risk for cardiovascular diseases (CVD) events compared with pregnant women without GDM. Gestational diabetes mellitus is defined as carbohydrate intolerance of varying degrees of severity with onset or first recognition during pregnancy (Metzger and Coustan 1998), which spontaneously improves after delivery or until the end of puerperium. The incidence of GDM occurs in about 3-5\% of all pregnancies and it is often associated with maternal risk factors such as overweight, advanced age, positive family history of DM type 2 and a previously complicated obstetric history. GDM is also associated with a high risk of subsequent development of maternal diabetes later in life (Bellamy et al. 2009, Feig et al. 2008, Kim et al. 2002) and cardiovascular disease (Sullivan et al. 2012).

\section{Standard 12 leads ECG}

\section{The heart rate}

The heart rate was observed to be significantly increased in DM 1 patients in comparison to healthy controls: $86.3 \pm 2.7 \mathrm{~ms}$ vs. $75.0 \pm 2.1 \mathrm{~ms}$ (Zdarska et al. 2007). This finding was confirmed later by Palova et al. (2010) who compared electrocardiograms of DM 1 patients with versus without cardiac autonomic neuropathy (CAN). In addition to this finding the study also proved significantly increased heart rate in DM 1 associated with CAN: $92.2 \pm 3.0 \mathrm{~ms}$. Increased heart rate in DM 1 patients with CAN was also described by Krahulec et al. (2002): 94.9 vs. 79.7 in DM 1 patients without CAN. The significantly increased heart rate was detected from $24 \mathrm{~h}$ Holter ECG also in DM 2 patients in comparison to healthy controls: $80.5 \pm 12.7 \mathrm{~ms}$ vs. $68.5 \pm 10.3 \mathrm{~ms}$ (Adebayo et al. 2014). Very similar results were observed in a cohort of patients suffering from DM 2 and CAN monitored by $24 \mathrm{~h}$ Holter examination by Balcioglu et al. (2007), who found the averaged HR in DM 2 patients with CAN $81.4 \pm 8.3$ vs. $76.0 \pm 12.8$ in DM 2 patients without CAN.

\section{The PQ interval}

No changes in the PQ interval were detected in studies focused on the ECG analysis in patients with DM 1, DM 2 or GDM. Neither CAN was reported to have any influence on the duration of the atrioventricular conduction. Slightly higher P wave voltage was reported by Krahulec et al. (2002) in DM 1 patients with CAN compared to DM 1 patients without CAN (0.13 vs. $0.11 \mathrm{mV})$.

\section{The QRS complex}

Shortening of the QRS complex was reported in DM 1 patients, the average duration of the QRS was detected to be $79.9 \pm 1.6 \mathrm{~ms}$ only while in the healthy controls it was found to be $89.9 \pm 2.7 \mathrm{~ms}$ (Zdarska et al. 2007). Even more shortened QRS complex was found in DM 1 patients with CAN $(75.5 \pm 1.6 \mathrm{~ms})$ which was a significant difference not only in comparison to the healthy controls but also to the DM 1 patients without CAN. On the other hand, controversial results were reported in women suffering from the GDM: while Medova et al. (2012) detected in GDM patients shorter QRS complex (82.0 $\pm 6.8 \mathrm{~ms}$ ) in comparison to $89.5 \pm 8.2 \mathrm{~ms}$ in healthy pregnant women and $90.8 \pm 7.9 \mathrm{~ms}$ in the control group of non-pregnant women, Zakovicova et al. (2014) 
found in GDM patients very similar duration of QRS complex $(82.9 \pm 15.7 \mathrm{~ms})$ but surprisingly shorter QRS in her cohort of non GDM pregnant women $(76.0 \pm 7.1 \mathrm{~ms})$. Simultaneously the duration of the QRS complex in the GDM group is correlating according to the same study with echocardiographic findings of posterior wall thickness and interventricular septal thickness.

\section{The QT and QTc intervals}

The findings regarding the QT and QTc intervals durations use to be also a little bit controversial. While Heller (2002) has detected in DM 1 patients QT and QTc intervals prolongation, Zdarska et al. (2007) have found

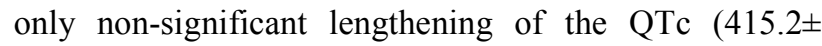
$4.1 \mathrm{~ms}$ vs. $401.4 \pm 6.1 \mathrm{~ms}$ in the healthy controls). The shortening of the QT interval reported by the same authors (374.0 $\pm 4.4 \mathrm{~ms}$ vs. $349.0 \pm 5.9 \mathrm{~ms}$ ) corresponded fully to the accelerated heart rate. Very similar results (shortening of the QT interval and non-significant prolongation of the QTc interval) were later found in DM 1 patients with CAN (Palova et al. 2010). On the other hand, Krahulec et al. (2002) have reported in CAN diabetics extended QTc interval length (422.4 vs. $396.3 \mathrm{~ms}$ ) in comparison to diabetic patients without neuropathy.

On the other hand, significantly prolonged duration of the QT interval was found in the group of patients with GDM ( $400.4 \pm 46.3 \mathrm{~ms})$ in comparison to the control group (370.0 $\pm 49.2 \mathrm{~ms})$. Moreover, positive correlation between QT interval and $\mathrm{HbAlC}$ level has been found. But it has to be noted that some ECG findings in pregnant women can be explained by changed spatial arrangement of the chest organs during pregnancy (Lechmanova et al. 2002).

Also animal experiments documented an influence of DM on the QTc: DM was proved to promote a significant prolongation in the QTc interval for instance in streptozotocin-induced diabetes in rats (Erbas et al. 2015).

\section{Body surface ECG maps}

ECG body surface isointegral, isopotential and isoarea maps (BSM) are the sensitive indications of local electrical depolarization and repolarization changes (Kittnar and Mlcek 2010). They allow to reveal even very subtle changes of the electrical heart field that cannot be detected by standard twelve lead ECG (Kittnar and Stovicek 1993, Pisvejcova et al. 2002).

\section{Depolarization maps}

Significantly decreased amplitudes of $\mathrm{R}$ waves and on the other hand, increased amplitudes of $\mathrm{Q}$ and $\mathrm{S}$ waves were found in DM 1 patients (Zdarska et al. 2007). Typically, the absolute value of maximum in the 50th ms of depolarization was reported to be only $815.8 \pm 78.9 \mu \mathrm{V}$ in DM 1 patients while in the healthy controls it was $1108.4 \pm 108.2 \mu \mathrm{V}$. Regarding the negative waves, the absolute value of minimum at the same time was found to be $-1510.0 \pm 110.8 \mu \mathrm{V}$ comparing to $-1160.4 \pm 131.3 \mu \mathrm{V}$ in the controls.

The activation time (ICHVAT), the speed of activation of the heart measured on the surface of thorax measured between the beginning of depolarization in an orthogonal lead and the $\mathrm{R}$ wave in the individual chest leads, was faster in DM 1 patients $(63.2 \pm 1.2 \mathrm{~ms})$ when compared to controls ( $70.5 \pm 2.0 \mathrm{~ms})$, which could be well explained by an activation of the sympathetic nervous system. Fully corresponding results were reported also in DM 1 patients with CAN (Palova et al. 2010).

Pronounced differences were also found in the duration of myocardial activation time in pregnant patients with GDM. Activation time of the ventricular myocardium in healthy pregnant women $(72.8 \pm 1.6 \mathrm{~ms})$ was longer than in women with GDM $(65.7 \pm 1.5 \mathrm{~ms})$. Moreover, ICHVAT significantly correlated with the thickness of the interventricular septum and posterior wall diameter in GDM patients (Zakovicova et al. 2014).

\section{Repolarization maps}

The repolarization isopotential map maximum (RIPMmax) was less positive and minimum (RIPMmin) less negative in DM 1 patients than in the controls showing the different rate of repolarization in DM 1 patients during the $\mathrm{T}$ wave resulting in significant general flattening of $\mathrm{T}$ waves. Typically, the absolute value of maximum in the 100th ms of repolarization in DM 1 patients was reported to be only $142.8 \pm 12.69 \mu \mathrm{V}$ while in the healthy controls it was $248.3 \pm 38.9 \mu \mathrm{V}$. Regarding the regions of a thorax with negative $\mathrm{T}$ waves, the absolute value of minimum at the same time was found to be $-119.0 \pm 23.3 \mu \mathrm{V}$ comparing to $-289.2 \pm 122.7 \mu \mathrm{V}$ in the controls. The changes in the repolarization maps do not depend on fact if the DM 1 patients suffer also from the CAN or not.

\section{Dispersion of QT interval}

Dispersion of QT interval (QTd) is defined as the difference between the maximal and minimal QT 
interval in any of the leads measured. QTd should be evaluated from the Body surface ECG mapping as consideration of greater number of leads for determination of QT dispersion appears to determine QTd more accurately than assessment in only 12 or even 6 precordial leads. The use of low number of leads was undoubtedly the main cause of repeatedly suggested poor reproducibility (Kautzner et al. 1994, Day et al. 1990). Enhanced accuracy for QT dispersion assessment from 12-lead ECG in comparison with only 6 precordial leads was reported as well (van de Loo et al. 1994, Higham and Campbell 1994). Our previous results have suggested that the QTd can be changed under pathological conditions (Kittnar et al. 2004) but also physiologically in a late pregnancy (Lechmanova et al. 2002). We have concluded therefore that QTd can reflect not only increased risk of serious tachyarrhythmias especially due to myocardial ischemia but it must be interpreted simply just as "an unspecific sign of changed course of repolarization" which seems to offer an explanation of increased QTd under many different circumstances (Masaki et al. 2006, Cafiero et al. 2011, Fauchier et al. 2005).

Dispersion of QT interval was detected to be increased in DM 1 patients: $115 \pm 36 \mathrm{~ms}$ vs. $34 \pm 12 \mathrm{~ms}$ in the healthy controls (Zdarska et al. 2007) and also in pregnant women suffering from GDM: QTd was proved to be significantly higher ( $107 \pm 25 \mathrm{~ms})$ both than in pregnant women with physiological pregnancy $(73 \pm$ $18 \mathrm{~ms}$ ) and than in the healthy non-pregnant women (34 $\pm 12 \mathrm{~ms})$.

Increased QTd seems to be resulting from a fact that shortening of the QT interval is not identical on the whole thorax surface but it is more pronounced in some thoracic regions. Zdarska et al. (2007) reported significantly shortened QT interval in all thoracic leads in DM 1 patients. But the study published later from the same laboratory revealed some interesting findings: In 68 thoracic surface leads out of 82 measured the QT duration was significantly shortened in the both groups of DM 1 patients when compared with controls. In 34 leads, the QT shortening was more pronounced in DM 1 patients with CAN than in DM 1 patients without CAN. In 34 other leads the shortening of QT duration was not different in the DM 1 patients with and without CAN in comparison with controls. In the resting 14 leads the significant shortening of the duration of QT interval was observed only in DM 1 patients with CAN and not in DM 1 patients without CAN (Palova et al. 2010).

\section{Heart rate variability}

Cardiovascular autonomic neuropathy (CAN) is the most studied form of DAN (diabetic autonomic neuropathy) and its prevalence varies between cohorts of diabetic patients, due to differences in the methodology (O'Brien et al. 1986, Vinik and Ziegler 2007, Ziegler et al. 1992). Changes in spectral analysis of heart rate variability, such as increased sympathetic activity and reduced parasympathetic activity of the autonomic vegetative system has already been described in the offspring of patients with DM type 2 (De Angelis et al. 2001, Laitinen et al. 1999) or pre-diabetic patients with insulin resistance (Lefrandt et al. 2000). One recent Finnish study (Heiskanen et al. 2010) showed that women with GDM and proper metabolic control compared with healthy pregnant women, did not have present significant changes in autonomic vegetative system, as it was previously assumed (Poyhonen-Alho et al. 2010).

Adebayo et al. (2014) have analyzed heart rate variability (HRV) in DM 2 patients in comparison to patients with arterial hypertension $(\mathrm{AH})$ and they found standard deviation of normal-to-normal RR intervals (SDNN) average (ms) significantly reduced in DM 2 patients $(81.03 \pm 26.33)$ compared to the $\mathrm{AH}$ patients without heart failure $(119.65 \pm 29.86)$ and with heart failure (107.03 \pm 62.50$)$. Similar findings were also noted when the root mean square of successive heartbeat interval differences (RMSSD) average (ms) was used to assess the $\mathrm{HRV}$, with significant reduction in DM 2 patients $(36.48 \pm 21.10)$ compared to $\mathrm{AH}$ patients without heart failure $(103.82 \pm 78.91)$ and with heart failure (99.45 \pm 88.14$)$. It is necessary to add that HRV was found to be reduced in hypertensive patients when compared with normotensive individuals (Menezes Ada et al. 2004). Moreover, using SDNN, Adebayo et al. (2014) have also detected a statistically significant variation between day and night HRV in DM 2 patients.

All HR variability indexes were found to be significantly decreased with CAN (Balcioglu et al. 2007). In patients with CAN, duration of DM 2 was found to be correlated positively with the Ewing score ( $r=0.753$, $\mathrm{p}<0.01)$ and negatively with $\mathrm{HR}$ variability indexes (SDNN, $\mathrm{r}=-0.358, \mathrm{p}<0.01$; SDNN index, $\mathrm{r}=-0.421$, $\mathrm{p}<0.01$; SDANN (standard deviation of the averages of normal-to-normal $\mathrm{RR}$ intervals), $\mathrm{r}=-0.294, \mathrm{p}<0.01$; square root of the mean squared differences of successive $\mathrm{NN}$ intervals, $\mathrm{r}=-0.361, \mathrm{p}<0.01$; triangular index, 
$\mathrm{r}=-0.468, \mathrm{p}<0.01)$, turbulence slope $(\mathrm{r}=-0.559, \mathrm{p}<0.01)$, and HR turbulence score $(\mathrm{r}=-0.485, \mathrm{p}<0.01)$.

No changes in HRV were found in pregnant women with GDM (Zakovicova et al. 2014): Parasympathetic activity assessed by spectral power in high frequency (HF) for three consecutive time intervals was $151 \pm 155,230 \pm 343,212 \pm 280 \mathrm{~ms}^{2}$ in the control group, which was comparable to $234 \pm 341,170 \pm 271$, $216 \pm 277 \mathrm{~ms}^{2}$ (NS) in women with GDM. Sympathetic activity evaluated as a LF / HF ratio (low frequency / high frequency) in three consecutive intervals was $1.9 \pm 1.7,1.9 \pm 1.6,1.7 \pm 1.9$ in the control group, which was comparable to $2.1 \pm 1.7,3.6 \pm 3.9$ and $2.1 \pm 2.3$ (NS) in women with GDM. Total parasympathetic activity evaluated as the sum of all three intervals (HF1 + HF2 + HF3) was $632 \pm 511 \mathrm{~ms}^{2}$ in the control group and $621 \pm 790$ $\mathrm{ms}^{2}$ in GDM group (NS). Total sympathetic activity evaluated as the sum of LF / HF ratio in all three intervals $(\mathrm{LF} 1 / \mathrm{HF} 1+\mathrm{LF} 2 / \mathrm{HF} 2+\mathrm{LF} 3 / \mathrm{HF} 3)$ was $5.5 \pm 4.1$ in the control group versus $7.9 \pm 6.0$ in the group of women with GDM (NS).

\section{Limitations}

All studies focused on ECG features that are characteristic for the DM patients have some similar limits derived from a fact that these features can be also modified by several other factors in addition to the DM. These factors include particularly concomitant diseases, different drugs used by the DM patients and obesity. That is why preferably studies in which concomitant diseases and obesity were listed among exclusion criteria were chosen for this review. Consequently with this selection also use of drugs that could influence particularly the heart rate and QT interval was supposed to be unlikely.

\section{Conclusions}

Repeatedly reported results showed in DM patients without cardiovascular complications the tachycardia, shortening of the QRS and QT intervals, increase of the dispersion of QT interval and decrease in $\mathrm{T}$ wave amplitude confirmed by the lower value of maximum and minimum in repolarization isopotential maps. The similar results of heart electric field parameters which we have obtained in the present work in DM 1 patients were also observed in the depressive patients treated with the tricyclic antidepressants (Slavicek et al. 1995, 1998, Paclt et al. 2003, Kittnar et al. 2004) or in panic disorder (Pisvejcova et al. 2002) due to activation of the sympathetic nervous system. Also shortening of activation time can be explained by an activation of the sympathetic nervous system. It can be therefore concluded that the electrocardiographic changes in DM patients are not specific and that they are particularly caused by an increased tone of the sympathetic nervous system which was indirectly confirmed by the HRV analysis.

Diabetes mellitus can be generally considered as a cardiovascular disease because it causes both microvascular and macrovascular complications (Alberti et al. 1978, Kannel et al. 1986, Alberti and Zimmet 1998, Beckman et al. 2002, Pickup and Williams 2003). Due to the sensitive neuropathy, the coronary artery disease in diabetic patients is frequently asymptomatic (Alberti and Zimmet 1998, Langer et al. 1991, Paillole et al. 1995, Wackers et al. 2004). Also twelve leads resting ECG can be within normal limits even in an advanced stage of coronary artery disease (Alberti and Zimmet 1998, Pickup and Williams 2003). In this respect, BSM might be relatively useful tool in coronary ischemia detection (Green et al. 1985, Kittnar and Stovicek 1993, Valouch et al. 2004) in asymptomatic diabetic patients.

\section{Conflict of Interest}

There is no conflict of interest.

\section{Acknowledgements}

Supported by PRVOUK-P35/LF1/5.

\section{References}

ADEBAYO RA, IKWU AN, BALOGUN MO, AKINTOMIDE AO, MENE-AFEJUKU TO, ADEYEYE VO, BAMIKOLE OJ, BISIRIYU LA, AJAYI OE, OGUNYEMI SA, OKETONA OA: Evaluation of the indications and arrhythmic patterns of 24 hour Holter electrocardiography among hypertensive and diabetic patients seen at OAUTHC, Ile-Ife Nigeria. Diabetes Metab Syndr Obes 7: 565-570, 2014.

ALBERTI KG, ZIMMET PZ: Definition, diagnosis and classification of diabetes mellitus and its complications. Part 1: diagnosis and classification of diabetes mellitus. Provisional report WHO Consultation. Diabet Med 15: 539$553,1998$. 
ALBERTI KG, ZIMMET P, DEFRONZO RA: International Textbook of Diabetes Mellitus. John Wiley, Ontario, 1978.

BALCIOGLU S, ARSLAN U, TURKOGLU S, OZDEMIR M, CENGEL A: Heart rate variability and heart rate turbulence in patients with type 2 diabetes mellitus with versus without cardiac autonomic neuropathy. $\mathrm{Am} \mathrm{J}$ Cardiol 100: 890-893, 2007.

BECKMAN JA, CREAGER MA, LIBBY P: Diabetes and atherosclerosis: epidemiology, pathophysiology and management. JAMA 287: 2570-2581, 2002.

BELLAMY L, CASAS JP, HINGORANI AD, WILLIAMS D: Type 2 diabetes mellitus after gestational diabetes: a systematic review and meta-analysis. Lancet 373: 1773-1779, 2009.

BREIDTHARDT T, CHRIST M, MATTI M, SCHRAFL D, LAULE K, NOVEANU M, BOLDANOVA T, KLIMA T, HOCHHOLZER W, PERRUCHOUD A, MUELLER C: QRS and QTc interval prolongation in the prediction of long-term mortality of patients with acute destabilized heart failure. Heart 93: 1093-1097, 2007.

BROOKSBY P, BATIN PD, NOLAN J, LINDSAY SJ, ANDREWS R, MULLEN M, BAIG W, FLAPAN AD, PRESCOTT RJ, NEILSON JMM, COWLEY AJ, FOX KAA: The relationship between QT intervals and mortality in ambulant patients with chronic heart failure. The United Kingdom heart failure evaluation and assessment of risk trial (UK-HEART). Eur Heart J 20: 1335-1341, 1999.

CAFIERO T, DI MINNO RM, DI IORIO C: QT interval and QT dispersion during the induction of anesthesia and tracheal intubation: a comparison of remifentanil and fentanyl. Minerva Anestesiol 77: 160-165, 2011.

De ANGelis C, PERElli P, TREZZA R, CASAGRANDE M, BISElli R, PANNITTERi G, MARINO B, FARRACE S: Modified autonomic balance in offsprings of diabetics detected by spectral analysis of heart rate variability. Metabolism 50: 1270-1274, 2001.

DE BRUYNE MC, HOES AW, KORS JA, HOFMAN A, VAN BEMMEL JH, GROBBEE DE: Prolonged QT interval predicts cardiac and all-cause mortality in the elderly. The Rotterdam Study. Eur Heart J 20: 278-284, 1999.

ERBAS O, SOLMAZ V, TASKIRAN D: Granulocyte colony-stimulating factor provides protection against cardiovascular autonomic neuropathy in streptozotocin-induced diabetes in rats. Diabetes Res Clin Pract 107: 377-383, 2015.

EWING DJ, BOLAND O, NEILSON JM, CHO CG, CLARKE BF: Autonomic neuropathy, QT interval lengthening, and unexpected deaths in male diabetic patients. Diabetologia 34: 182-185, 1991.

FAUCHIER L, DOUGLAS J, BABUTY D, COSNAY P, FAUCHIER JP: QT dispersion in nonischemic dilated cardiomyopathy. A long-term evaluation. Eur J Heart Fail 7: 277-282, 2005.

FEIG DS, ZINMAN B, WANG X, HUX JE: Risk of development of diabetes mellitus after diagnosis of gestational diabetes. CMAJ 179: 229-234, 2008.

GREEN LS, LUX RL, HAW CW, WILLIAMS RR, HUNT SC, BURGESS MJ: Effect of age, sex and body habitus on QRS and ST-T potential maps of 1100 normal subjects. Circulation 71: 244-253, 1985.

HEISKANEN N, SAARELAINEN H, KARKKAINEN H, VALTONEN P, LYYRA-LAITINEN T, LAITINEN T, VANNINEN E, HEINONEN S: Gestational diabetic patients with adequate management have normal cardiovascular autonomic regulation during the third trimester of pregnancy and 3 months after delivery. J Diabetes Complications 24: 234-241, 2010.

HELLER SR: Abnormalities of the electrocardiogram during hypoglycaemia: the cause of the dead in bed syndrome? Int J Clin Pract Suppl 129: 27-32, 2002.

HIGHAM PD, CAMPBELL RWF: QT dispersion. Br Heart J 71: 508-510, 1994.

JAVORKA M, JAVORKOVA J, TONHAJZEROVA I, JAVORKA K: Parasympathetic versus sympathetic control of the cardiovascular system in young patients with type 1 diabetes mellitus. Clin Physiol Funct Imaging 25: 270274, 2005.

KANNEL WB, NEATON JD, WENWORTH D, THOMAS HE, STAMLER J, HULLEY SB, KJELSBERG MO: Overall and coronary heart disease mortality rates in relation to major risk factors in 325348 men screened for the MRFIT. Multiple Risk Factor Intervention Trial. Am Heart J 112: 825-836, 1986.

KHOHARO HK, HALEPOTO AW: QTc-interval, heart rate variability and postural hypotension as an indicator of cardiac autonomic neuropathy in type 2 diabetic patients. J Pak Med Assoc 62: 328-331, 2012.

KAUTZNER J, YI G, CAMM AJ, MALIK M: Short- and long-term reproducibility of QT, QTc and QT dispersion measurement in healthy subjects. Pacing Clin Electrophysiol 17: 928-937, 1994. 
KIM C, NEWTON KM, KNOPP RH: Gestational diabetes and the incidence of type 2 diabetes: a systematic review. Diabetes Care 25: 1862-1868, 2002.

KITTNAR O, MLCEK M: Analysis of the electrical heart field. Physiol Res 59 (Suppl 1): S19-S24, 2010.

KITTNAR O, STOVICEK P: Contemporary body surface potential mapping in electrocardiology and its perspectives. Physiol Res 42: 141-143, 1993.

KITTNAR O, PACLT I, MLCEK M, SLAVICEK J, DOHNALOVÁ A, HAVRANEK S, BRIZMAN E, KITZLEROVÁ E, PISVEJCOVA K: QT dispersion and electrical heart field morphology in patients treated with dosulepin. Physiol Res 53: 379-386, 2004.

KRAHULEC B, MIKEŠ Z, BALAŽOVJECH I: The effect of cardiovascular autonomic neuropathy on resting ECG in type 1 diabetic patients. Bratisl Lek Listy 103: 54-58, 2002.

LAITINEN T, VAUHKONEN IK, NISKANEN LK, HARTIKAINEN JE, LANSIMIES EA, UUSITUPA MI, LAAKSO M: Power spectral analysis of heart rate variability during hyperinsulinemia in nondiabetic offspring of type 2 diabetic patients: evidence for possible early autonomic dysfunction in insulin-resistant subjects. Diabetes 48: 1295-1299, 1999.

LECHMANOVA M, PARIZEK A, HALASKA M, SLAVICEK J, KITTNAR O: Changes of the electrical heart field and hemodynamic parameters in the 34th to 40th weeks of pregnancy and after delivery. Arch Gynecol Obstet 266: 145-151, 2002.

LEFRANDT JD, MULDER MC, BOSMA E, SMIT AJ, HOOGENBERG K: Inverse relationship between blood glucose and autonomic function in healthy subjects. Diabetes Care 23: 1862-1864, 2000.

MARQUES JL, GEORGE E, PEACEY SR, HARRIS ND, MACDONALD IA, COCHRANE T, HELLER SR: Altered ventricular repolarization during hypoglycaemia in patients with diabetes. Diabet Med 14: 648-654, 1997.

MASAKI N, TAKASE B, MATSUI T, KOSUDA S, OHSUZU F, ISHIHARA M: QT peak dispersion, not QT dispersion, is a more useful diagnostic marker for detecting exercise-induced myocardial ischemia. Heart Rhythm 3: 424-432, 2006.

MASER RE, MITCHELL BD, VINIK AI, FREEMAN R: The association between cardiovascular autonomic neuropathy and mortality in individuals with diabetes: a meta-analysis. Diabetes Care 26: 1895-1901, 2003.

MEDOVA E, FIALOVA E, MLCEK M, SLAVICEK J, DOHNALOVA A, CHARVAT J, ZAKOVICOVA E, KITTNAR O: QT dispersion and electrocardiographic changes in women with gestational diabetes mellitus. Physiol Res 61 (Suppl 2): S49-S55, 2012.

MENEZES ADA S Jr, MOREIRA HG, DAHER MT: Analysis of heart rate variability in hypertensive patients before and after treatment with angiotensin II-converting enzyme inhibitors. Arq Bras Cardiol 83: 169-172, 2004.

O'BRIEN IA, O'HARE JP, LEWIN IG, CORRALL RJ: The prevalence of autonomic neuropathy in insulin-dependent diabetes mellitus: a controlled study based on heart rate variability. $Q J \mathrm{Med}$ 61: 957-967, 1986.

PACLT I, SLAVÍČEK J, DOHNALOVÁ A, KITZLEROVÁ E, PIŠVEJCOVÁ K: Electrocardiographic dosedependent changes in prophylactic doses of dosulepine, lithium and citalopram. Physiol Res 52: 311-317, 2003.

PAILLOLE C, RUIZ J, JULIARD JM, LEBLANC H, GOURGON R, PASSA P: Detection of coronary artery disease in diabetic patients. Diabetologia 38: 726-731, 1995

PALOVA S, SZABO K, CHARVAT J, SLAVICEK J, MEDOVA E, MLCEK M, KITTNAR O: ECG body surface mapping changes in type 1 diabetic patients with and without autonomic neuropathy. Physiol Res 59: 203-209, 2010.

PICKUP JC, WILLIAMS G: Handbook of Diabetes. Blackwell Publishing, Oxford, 2003.

PISVEJCOVA K, PACLT I, SLAVICEK J, KITTNAR O, DOHNALOVA A, KITZLEROVÁ E: Electrocardiogram, vectocardiogram and body surface maps in patients with panic disorder. Physiol Res 51: 401-406, 2002.

POYHONEN-ALHO M, VIITASALO M, NICHOLLS MG, LINDSTROM BM, VAANANEN H, KAAJA R: Imbalance of the autonomic nervous system at night in women with gestational diabetes. Diabet Med 27: 988 994, 2010.

ROSSING P, BREUM L, MAJOR-PEDERSEN A, SATO A, WINDING H, PIETERSEN A, KASTRUP J, PARVING HH: Prolonged QTc interval predicts mortality in patients with Type 1 diabetes mellitus. Diabet Med 18: 199$205,2001$. 
RUTTKAY-NEDECKY I: The effect of the autonomic nervous system on the heart. Electrocardiographic evaluation: problems and concerns. Cardiology 10: 42-48, 2001.

SLAVICEK J, PACLT I, KITTNAR O, DOHNALOVA A: Some electrocardiographic side effects of antidepressant drugs. Cor Vasa 37: 212-216, 1995.

SULLIVAN SD, UMANS JG, RATNER R: Gestational diabetes: implications for cardiovascular health. Curr Diab Rep 12: 43-52, 2012.

VALOUCH P, SLAVÍČEK J, TICHÝ JA, PETERKA Z, KITTNAR O, TROJAN S, TREFNÝ Z, NOVÁK V: Electrocardiographic body surface maps (BSM) in patients with ischemic heart disease examined by coronary angiography. Prague Medical Report (Sborn Lék) 105: 131-140, 2004.

VAN DE LOO A, ARENDTS W, HOHNLOSER SH: Variability of QT dispersion measurements in the surface electrocardiogram in patients with acute myocardial infarction and in normal subjects. Am J Cardiol 74: 1113 $1118,1994$.

VINIK AI, ZIEGLER D: Diabetic cardiovascular autonomic neuropathy. Circulation 115: 387-397, 2007.

WACKERS FJ, YOUNG LH, INZUCCHI SE, CHYUN DA, DAVEY JA, BARRET EJ, TAILLEFER R, WITTLIN SD, HELLER GU, FILIPCHUK N, ENGEL S, RATNER RE: Detection of silent myocardial ischemia in asymptomatic diabetic subjects, the DIAD study. Diabetes Care 27: 1954-1961, 2004.

ZAKOVICOVA E, KITTNAR O, SLAVICEK J, MEDOVA E, SVAB P, CHARVAT J: ECG body surface mapping in patients with gestational diabetes mellitus and optimal metabolic compensation. Physiol Res 63 (Suppl 4): S479-S487, 2014.

ZDARSKA D, PELISKOVA P, CHARVAT J, SLAVICEK J, MLCEK M, MEDOVA E, KITTNAR O: ECG body surface mapping (BSM) in type 1 diabetic patients. Physiol Res 56: 403-410, 2007.

ZELLWEGER MJ, PFISTERER ME: Silent coronary artery disease in patients with diabetes mellitus. Swiss Med Wkly 131: 427-432, 2001.

ZIEGLER D, GRIES FA, SPULER M, LESSMANN F: The epidemiology of diabetic neuropathy. Diabetic Cardiovascular Autonomic Neuropathy Multicenter Study Group. J Diabetes Complications 6: 49-57, 1992. 